\title{
The effects of black cohosh on the regulation of estrogen receptor $(E R \alpha)$ and progesterone receptor (PR) in breast cancer cells
}

This article was published in the following Dove Press journal: Breast Cancer - Targets and Therapy

\author{
Monica Szmyd ${ }^{1-3}$ \\ Victoria Lloyd ${ }^{1-3}$ \\ Kelly Hallman ${ }^{1-3}$ \\ Katie Aleck ${ }^{1-3}$ \\ Viktoria Mladenovik ${ }^{1-3}$ \\ Christina McKee ${ }^{1-3}$ \\ Mia Morse ${ }^{1-3}$ \\ Tyler Bedgood ${ }^{1-3}$ \\ Sumi Dinda ${ }^{1-3}$ \\ 'Biomedical and Therapeutic \\ Sciences, School of Health Sciences, \\ ${ }^{2}$ Prevention Research Center, ${ }^{3}$ Center \\ of Biomedical Sciences, Oakland \\ University, Rochester, MI, USA
}

Correspondence: Sumi Dinda

School of Health Sciences, 3164 HHB,

433 Meadow Brook Road, Oakland

University, Rochester, MI 48309-4476,

USA

Tel +I 2483648676

Fax + I 2483648657

Email sdinda@oakland.edu

\begin{abstract}
The North American plant Cimicifuga racemosa, also known as black cohosh (BC), is a herb that recently has gained attention for its hormonal effects. As the usage of hormone replacement therapy is declining due to its adverse effects in women with cancer, many are turning to herbal remedies like $\mathrm{BC}$ to treat menopausal symptoms. It is crucial to determine whether the effects of $B C$ involve estrogen receptor-alpha $(E R \alpha)$. Previous studies from our laboratory have shown ER $\alpha$ to be a possible molecular target for BC. In this study, we examined the effects of $\mathrm{BC}(8 \%$ triterpene glycosides) alone and in combination with hormones and antihormones on the cellular viability, expression of $\mathrm{ER} \alpha$ and progesterone receptor (PR)-A/B, and cytolocalization of ER $\alpha$ in ER (+) and PR-A/B (+) T-47D breast cancer cells. Cells were cultured and proteins were extracted and quantified. Western blot analysis revealed alterations in the expression of ER $\alpha$ and PR after treatment with BC $(5-100 \mu \mathrm{M})$. BC induced a concentration-dependent decrease in $\mathrm{ER} \alpha$ and PR protein levels when compared to the control. Image cytometric analysis with propidium iodide staining was used to enumerate changes in T-47D cell number and viability. A decrease in T-47D cell viability was observed upon treatment with 5-100 $\mu \mathrm{M} \mathrm{BC}$. The ideal concentration of $\mathrm{BC}(100 \mu \mathrm{M})$ was used in combination with hormones and antihormones in an effort to further understand the possible similarities between this compound and other known effectors of ER $\alpha$ and PR. After a 24-hour concomitant treatment with and/or in combination of BC, estradiol, ICI 182, 780, and Tamoxifen, downregulation of ER $\alpha$ and PR protein levels was observed. Delineating the role of BC in the regulation of ER $\alpha, \mathrm{PR}$, as well as its mechanisms of action, may be important in understanding the influence of $\mathrm{BC}$ on hormone receptors in breast cancer.
\end{abstract}

Keywords: black cohosh, breast cancer, ER $\alpha$, progesterone receptor, hormone replacement therapy

\section{Introduction}

A woman's health is greatly impacted by hormone levels to maintain physiological order so vital biological functions are carried out. The main sex hormones in women are estrogen and progesterone. Estrogen is responsible for secondary sex characteristics and cell growth and progesterone balances estrogen's proliferative effect. ${ }^{1}$ Hormonal imbalances may lead to women becoming susceptible to health issues, such as breast cancer. Breast cancer is the leading cause of death among women over the age of 50 in USA. ${ }^{2}$ Estrogen receptor (ER) expression is the main indicator of potential responses to hormonal therapy, and $\sim 70 \%$ of human breast cancers are hormone dependent and ERpositive. ${ }^{2}$ Recently, there has been a rise in interest regarding the benefits of hormone replacement therapy, motivating researchers to find effective, nonhormonal approaches 
to treat menopause-related symptoms. Complementary and alternative medicine, such as botanic medicines, has grown increasingly popular in the last decade as an approach to hormone therapy. ${ }^{3}$ Sales of herbal dietary supplements for personal well-being reached $\$ 6.4$ billion in $2014 .{ }^{4}$ According to HerbalGram's 2014 Herb Market Report, black cohosh (BC) ranked fourth as one of the most popular botanicals, especially for menopausal symptom relief. ${ }^{4}$

Cimicifuga racemosa, also known as BC, is a herbaceous perennial plant native to North America. ${ }^{5} \mathrm{BC}$ has been used for centuries across numerous cultures for its great range of health benefits. It has been widely used as a pain relieving, fever reducing, and anti-inflammatory agent, as well as for its ability to treat infectious diseases. Recently, BC has acquired significant attention for its hormonal effects, which have the possibility to alleviate female medical conditions, including menopausal symptoms, such as hot flashes, profuse sweating, and sleep disturbances. ${ }^{6,7}$

As the usage of hormone replacement therapy is declining due to its adverse effects in cancer patients, women are turning to herbal remedies such as BC to treat their menopausal conditions. ${ }^{89}$ Studies indicate that flavonoids, like BC, may act as a selective estrogen receptor modulator (SERM), thus inducing inhibitory growth effects on hormone-dependent cancer cells. ${ }^{10}$ SERMs are compounds that interact with intracellular ERs in target organs, such as skeletal or reproductive organs, where they have agonistic or antagonistic effects, respectively. SERMs are being intensively studied and have proven to be an effective treatment for different conditions related to postmenopausal women's health, such as hormone-responsive cancer. ${ }^{11}$

Steroid hormones, such as estrogen, have welldocumented effects on the proliferation of breast tissue. As estradiol $\left(E_{2}\right)$ diffuses across the epithelial membrane of breast tissue, it binds to its receptor in the nucleus causing further activation of estrogen-responsive genes. Of the two ER types, ER $\alpha$ has clinical relevance which is coded by ESR1 gene. A similar molecular pathway is observed with progesterone on progesterone receptors (PRs). Two isoforms are expressed, PR-A and PR-B, both of which are coded by the same PR gene, but PR-A is a truncated version of PR-B. ${ }^{12}$ Transcription of both isoforms is indirectly induced through activation of ER. PR-A serves as a transcriptional inhibitor of steroid hormone receptors and PR-B functions to provide transcriptional activation of progesterone-responsive genes. ${ }^{13}$ The regulation of cellular proliferation occurs by cell cycle-specific actions in cells undergoing G1 phase. Estrogen has early stimulatory effects in the G1 phase allowing only limited time for antiestrogens to inhibit further growth. As estrogen binds to its ER, it allows for further activation and continued proliferation of breast tissue. ${ }^{14}$ It is vital to determine whether the effects of BC encompass ER $\alpha$ and PR-A/B. Previous studies from our laboratory have shown ER $\alpha$ to be a possible molecular target for breast cancer. ${ }^{15,16}$

In this study, we have examined the effects of $8 \% \mathrm{BC}$ alone and in combination with hormones and antihormones on the cellular viability, expression of ER $\alpha$ and PR-A/B, and cytolocalization of ER $\alpha$ in ER (+) and PR-A/B (+) T-47D breast cancer cells. Understanding the role of $\mathrm{BC}$ during regulation of $\mathrm{ER} \alpha$ and $\mathrm{PR}-\mathrm{A} / \mathrm{B}$, as well as its mechanisms of action, may be crucial in understanding the impact that $\mathrm{BC}$ has on steroid hormone receptors in breast cancer.

\section{Materials and methods}

\section{Cell culture and treatment with ligands}

The human breast cancer cell line, T-47D, was obtained from American Type Culture Collection (Manassas, VA, USA). These cells were routinely cultured following the same protocol as previous studies in our laboratory. ${ }^{15,17-19}$ Cells were incubated at $37^{\circ} \mathrm{C}$ in an incubator with $5 \% \mathrm{CO}_{2}$ in RPMI-1640 media (Hyclone, Logan, UT, USA) and 10\% fetal bovine serum (FBS; Hyclone) that contain growth factors and exogenous steroids which assist in cell growth and proliferation. The medium was replaced every 48 hours. Once the cells acquired proper confluency, the medium was changed to a $5 \%$ dextran-coated charcoal (DCC)-stripped FBS. The purpose of the stripped serum is to diminish cells of any endogenous steroids and growth factors. Therefore, this lets the cells remain at their basal metabolic rate during treatment with the compound, which will certify that the effects perceived on the cells are exclusively due to the treatment and not due to other factors within the media. The cells were maintained in charcoal-stripped serum for 6 days. On the sixth day, the 6-well plates were treated with $2 \mu \mathrm{L}$ of ligands for 24 hours. Varying concentrations $(5-100 \mu \mathrm{M})$ of $\mathrm{BC}$ were used for the concentration dependency studies. For the hormone studies, hormones and antihormones were combined with $100 \mu \mathrm{M}$ BC.

\section{Protein extraction and quantification}

After the treatment duration of 24 hours, the cells' proteins were extracted following the same protocol as in previous experiments done in our laboratory. ${ }^{15,17-19}$ The 5\% stripped serum was aspirated, washed with Hanks balanced salt solution, and aspirated. The cells were lysed with an extraction buffer composed of radioimmunoprecipitation assay lysis 
buffer, PMSF, and protease inhibitor cocktail (Santa Cruz Biotechnology, Inc, Dallas, TX, USA). After the addition of the buffer, a high-speed supernatant of the extracts was prepared by centrifuging at $15,000 \mathrm{rpm}$ for 15 minutes at $4^{\circ} \mathrm{C}$. The supernatant of each sample was separated and used to prepare a protein assay based on the Bradford method (Bio-Rad Laboratories Inc, Hercules, CA, USA). The data generated by the protein assay were used to quantify and normalize the amount of protein within each sample.

\section{Sodium dodecyl sulfate-polyacrylamide gel electrophoresis (SDS-PAGE) and Western blot analyses}

The extracted proteins were then separated according to molecular weight by running SDS-PAGE, therefore allowing the protein of interest to be isolated using Western blot analysis. The same technique performed in previous studies in our laboratory was utilized..$^{15,17-19}$ Protein in the supernatant was heated to $85^{\circ} \mathrm{C}$ for 3 minutes. Each sample was then loaded into $7.5 \%$ polyacrylamide gel in equivalent concentrations as determined from the previously mentioned protein assay. A method known as electroblotting allowed the proteins in the gel to be transferred to an Immobilon PVDF membrane (EMD Millipore, Billerica, MA, USA). The membrane was then washed for 30 minutes in Tris-buffered saline (TBS)-Tween $(0.1 \%)$ and then blocked with $5 \%$ nonfat dry milk for 1 hour to block nonspecific proteins on the membrane. In order to detect ER $\alpha$ and PR-A/B, the primary antibodies - anti-mouse monoclonal antibody (Santa Cruz Biotechnology, Inc) and anti-rabbit PR-A/B polyclonal (Cell Signaling Technology Inc, Danvers, MA, USA) - were used followed by 30 minutes with three changes of TBS-Tween and re-blocked with 5\% nonfat dry milk for 30 minutes. In order to distinguish the primary antibodies, secondary goat-anti-mouse $\mathrm{IgG}_{2 \mathrm{~A}}$ antibody and secondary anti-rabbit antibody (Jackson Laboratory, Bar Harbor, ME, USA) were used, respectively. The specific bands for $\mathrm{ER} \alpha$ and PR-A/B could be visualized by the enhanced chemiluminescence technique according to instructions from Advansta Inc (Menlo Park, CA, USA). The protein bands were then viewed using the Bio-Rad ChemiDoc imaging system (Bio-Rad Laboratories Inc). After immunoblotting, the PVDF membranes were stained with Coomassie Blue to confirm accurate normalization against total protein levels and full transfer of protein. The protein band density from the Western blots was then quantified using the Image Studio Lite program version 3.1 (LI-COR Biosciences, Lincoln, NE, USA).

\section{Reverse transcription quantitative real-time polymerase chain reaction (RT-qPCR)}

Total RNA was extracted from T-47D cells using "Trizol" reagent (Thermo Fisher Scientific, Waltham, MA, USA) as per the manufacturer's protocol. gDNA-free total RNA was reverse transcribed using iScript cDNA Synthesis Kit (Bio-Rad Laboratories Inc) according to the manufacturer's instructions. Prior to RT-qPCR analysis, cDNA was diluted 10-fold in PCR-grade water. qPCR of reverse transcribed cDNA (RT-qPCR) was performed in 96-well format in the Bio-Rad CFX384 Real Time System. The assay included no template, no template during RT, and no RT controls to detect reagent contamination and presence of genomic DNA. The 96-well plates were arranged in randomized treatment maximization blocks. For data analysis, the quantification cycle $(\mathrm{Cq})$ value was determined and specific gene expression normalized to endogenous control using $\Delta \Delta \mathrm{Cq}$ method. Expression of ACTB and HPRT-1 genes was set as endogenous controls (reference genes). The normalized $\Delta \mathrm{Cq}$ from treated samples was compared with the stripped control (Cs) to obtain $\Delta \Delta \mathrm{Cq}$ values and used to calculate relative fold change compared with control. ESR1 mRNA levels were determined by RT-qPCR. T-47D cells were treated in the presence or absence of $100 \mu \mathrm{M}$ $\mathrm{BC}, \mathrm{E}_{2}$, and ICI 182, 780 (ICI) for 24 hours. Results are shown as the mean \pm standard error of the mean (SEM) of at least three independent experiments with three replicates in each experiment.

\section{Cell viability assays}

Cell viability assays were used to show the total number of live cells post a 6-day treatment of ligands at varying concentrations. The same protocol was followed as from previous studies in our laboratory. ${ }^{17-19}$ Studies were organized in 12-well culture plates with an initial cell count of $3.0 \times 10^{4}$ cells per well. The cells were maintained in $1 \mathrm{~mL}$ culture medium containing $10 \%$ FBS for 2 days. For the next 6 days, growth factor media were replenished with DCCFBS media and treated with ligands over 2-day intervals for 6 days. Treatments of 5-100 $\mu \mathrm{M} \mathrm{BC}$ were implemented, followed by performance of a cell viability assay. The cells were trypsinized, extracted from their wells, stained with propidium iodide, and underwent image cytometry using the Cellometer Vision CBA software (Nexcelom Bioscience LLC, Lawrence, MA, USA). 


\section{Immunofluorescence and confocal microscopy}

T-47D cells were plated on coverslips in 12-well plates as described in the "Cell viability assays" section. Immunolabeling was performed for ER $\alpha$ in T-47D cells. The distribution of three-dimensional fluorescent structures was examined using a Nikon Digital Eclipse C1 plus confocal microscope (Nikon Instruments Inc, Melville, NY, USA). NIS Elements AR software (Nikon Instruments) was used for noise reduction and three-dimensional reconstruction of the images. The same protocol was followed as previous studies performed in our laboratory. ${ }^{15}$

\section{Statistical analyses}

The results are expressed as mean \pm SEM. Statistical significance was determined by Kruskal-Wallis test followed by post hoc analysis using Mann-Whitney $U$ test. Differences are considered significant at $p<0.05$. In all figures, ${ }^{*} p<0.05,{ }^{*} * p<0.01$, $* * * p<0.001$. Statistical analyses were carried out using SPSS for Windows, version 11.5 (SPSS Inc, Chicago, IL, USA).

\section{Results}

\section{Concentration-dependent effects of BC on ER $\alpha$ levels and PR-A/B levels}

Figure 1 displays the data of the concentration dependency study on the levels of ER $\alpha$ protein. T-47D cells were cultured in RPMI-1640 medium supplemented with 10\%
FBS for 2 days followed by 6 days in media containing 5\% DCC-stripped FBS with media changed every 48 hours. On the seventh day, cells were treated with BC for 24 hours at concentrations of 5-100 $\mu \mathrm{M}$. Concentration-dependent downregulation of ER $\alpha$ protein expression was detected as compared to the control (denoted $\mathrm{Cs}$ ), which was grown in 5\% charcoal-stripped serum during the experiment. The results indicate an optimal concentration at $100 \mu \mathrm{M} \mathrm{BC}$ due to the decrease in ER $\alpha$ protein expression that is detected with a $57 \%$ decrease compared to the control.

Figure 2 represents the results of PR-A/B levels when T-47D cells were cultured, as previously described, and treated for 24 hours with varying concentrations of BC from 5 to $100 \mu \mathrm{M}$. With increasing concentrations of $\mathrm{BC}$, the results indicate that $\mathrm{BC}$ exerts a concentration-dependent downregulation of PR-A/B levels. The greatest decrease of protein expression is observed when cells were treated with $100 \mu \mathrm{M}$ BC. The results from the concentration-dependent effects of $\mathrm{BC}$ on both $\mathrm{ER} \alpha$ and $\mathrm{PR}-\mathrm{A} / \mathrm{B}$ protein expression indicate $100 \mu \mathrm{M} B C$ to be the optimal concentration to test $\mathrm{ER} \alpha$ and PR-A/B expression in the presence of hormones and antihormones for this study.

\section{Concentration-dependent effects of BC on cell viability}

Cellular viability assays determine the amount of cells that maintain their viability after treatment with varying $\mathrm{BC}$

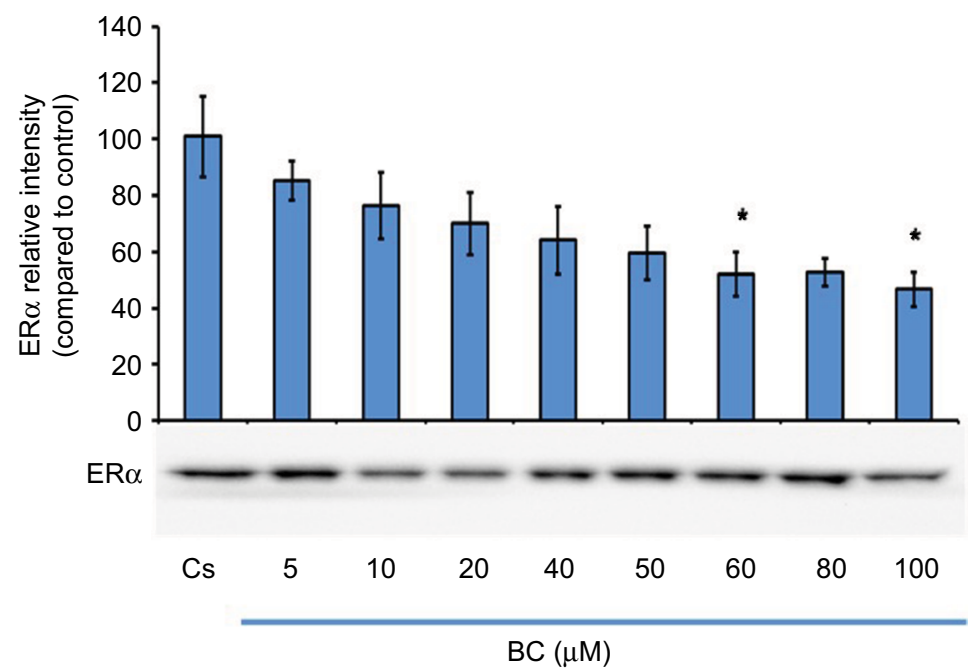

Figure I Concentration-dependent effects of BC on ER $\alpha$ levels.

Notes: T-47D cells were cultured in RPMI-1640 medium supplemented with 10\% FBS for 2 days followed by 6 days in media containing $5 \%$ DCC-stripped FBS with media changed every 48 hours. On the seventh day, cells were treated with BC for 24 hours at concentrations of 5-100 $\mu$ M. Cellular protein extracts were prepared followed by protein quantification, SDS-PAGE, and Western blot analysis. The control lane, Cs, represents cells grown in the absence of ligands in media containing $5 \%$ DCC-stripped FBS. The relative intensity of ER $\alpha$ protein, as compared to $C s$, is displayed as the mean \pm SEM. The asterisk indicates significant difference with respect to the control. * $p<0.05$ (Kruskal-Wallis test followed by post hoc analysis using Mann-Whitney $U$ test). Three independent experiments are displayed in the representative blots.

Abbreviations: BC, black cohosh; Cs, control; ER $\alpha$, estrogen receptor-alpha; SEM, standard error of the mean; SDS, sodium dodecyl sulfate; PAGE, polyacrylamide gel electrophoresis; DCC, dextran-coated charcoal; FBS, fetal bovine serum. 
concentrations. Figure 3 demonstrates the results of cellular influence of $\mathrm{BC}$ at varying concentrations. To determine this, T-47D cells were cultured in 12-well plates with 30,000 cells per well in FBS media containing growth factors for 2 days. DCC-stripped FBS containing media supplements with ligands of varying concentrations from 5 to $100 \mu \mathrm{M} B C$ were

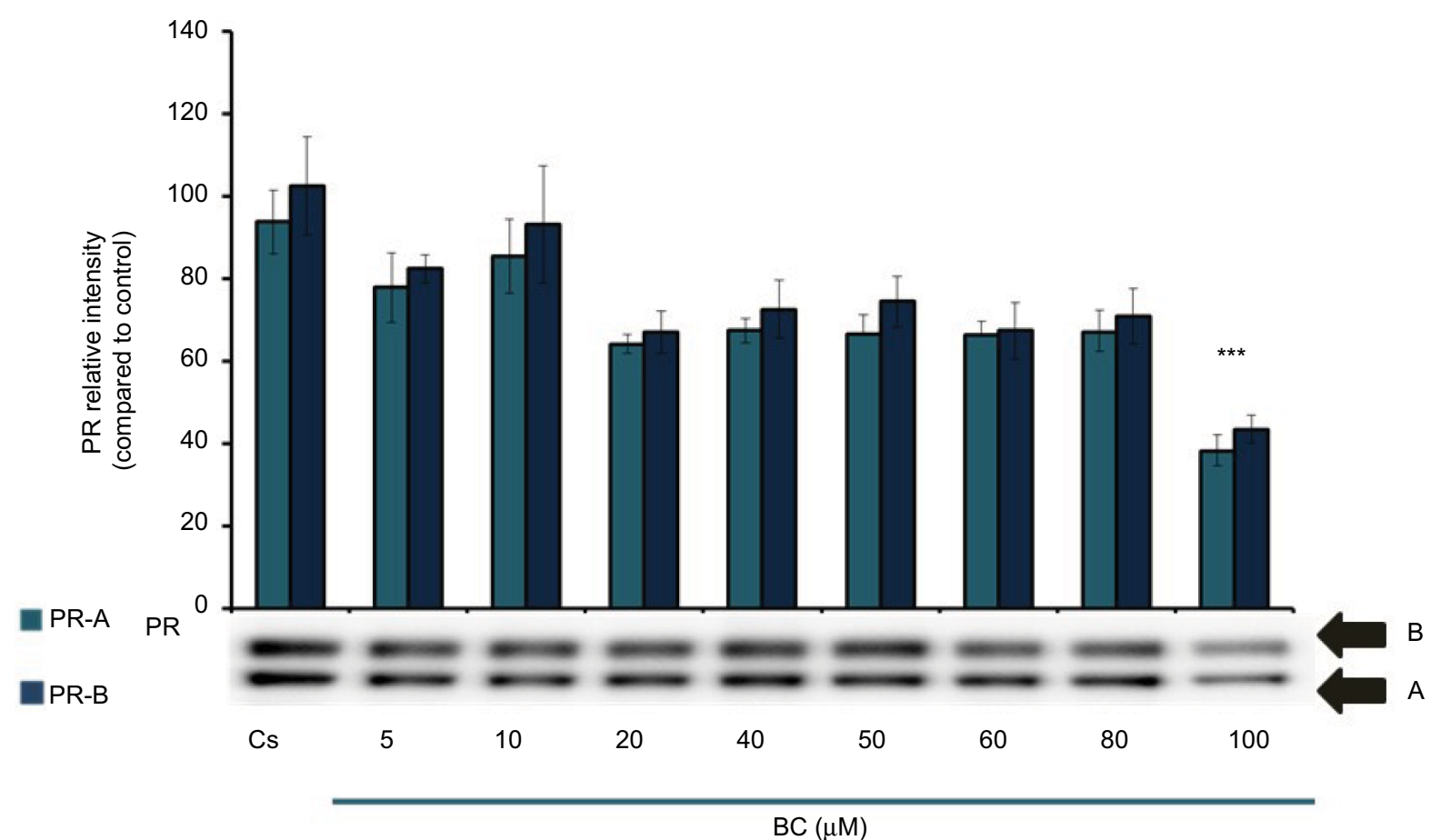

Figure 2 Concentration-dependent effects of BC on PR-A/B levels.

Notes: T-47D cells were cultured in RPMI- 1640 medium supplemented with 10\% FBS for 2 days followed by 6 days in media containing $5 \%$ DCC-stripped FBS with media changed every 48 hours. On the seventh day, cells were treated with BC for 24 hours at concentrations of 5-100 $\mu$ M. Cellular protein extracts were prepared followed by protein quantification, SDS-PAGE, and Western blot analysis. The control lane, Cs, represents cells grown in the absence of ligands in media containing $5 \%$ DCC-stripped FBS. The relative intensity of PR-A/B protein, as compared to Cs, is displayed as the mean \pm SEM. The asterisk indicates significant difference with respect to the control. $*_{* *}^{*} p<0.00 \mathrm{I}$ (Kruskal-Wallis test followed by post hoc analysis using Mann-Whitney $U$ test). Three independent experiments are displayed in the representative blots.

Abbreviations: BC, black cohosh; Cs, control; SEM, standard error of the mean; SDS, sodium dodecyl sulfate; PAGE, polyacrylamide gel electrophoresis; DCC, dextrancoated charcoal; FBS, fetal bovine serum; PR, progesterone receptor.

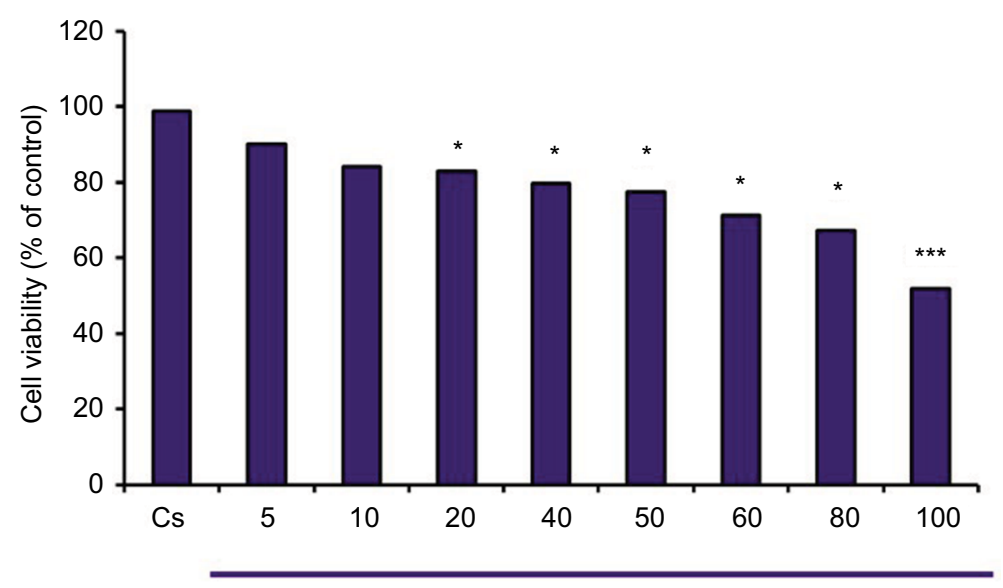

$\mathrm{BC}(\mu \mathrm{M})$

Figure 3 Concentration-dependent effects of $B C$ on cell viability.

Notes: T-47D cells were cultured in 12-well plates containing $\sim 30,000$ cells per well. For 2 days, cells were maintained in $10 \%$ FBS media containing growth factors for growth. For the following 6 days, growth factor media were replenished with DCC-FBS media and treated with ligands at 2-day intervals over 6 days. The treatments consisted of 5-100 $\mathrm{M} \mathrm{BC}$ and were followed by a cell viability assay utilizing propidium iodide staining and image cytometry via the Nexcelom Cellometer Vision on the seventh day. ${ }^{*} p<0.05$ and ${ }^{* * *} p<0.001$ (Kruskal-Wallis test followed by post hoc analysis using Mann-Whitney $U$ test). Three independent experiments are displayed in the graph.

Abbreviations: BC, black cohosh; Cs, control; DCC, dextran-coated charcoal; FBS, fetal bovine serum. 
added and replaced for 6 days in 2-day intervals followed by extraction. Image cytometric analysis with propidium iodide staining was used to quantify alterations in T-47D cell number and viability via the Nexcelom Cellometer. A 23\%-61\% decrease in T-47D cell viability was observed post-incubation of 5-100 $\mu \mathrm{M} \mathrm{BC}$, respectively. Results indicate a significant decrease in cell viability when treated with $20-100 \mu \mathrm{M} \mathrm{BC}$, with the greatest significance witnessed at $100 \mu \mathrm{M} B C$.

\section{Hormonal and antihormonal effects of $B C$ on $E R \alpha$ levels and PR-A/B levels}

T-47D cells were cultured in RPMI-1640 medium supplemented with $10 \%$ FBS for 2 days, followed by 6 days in media containing 5\% DCC-stripped FBS with media changed every 48 hours. On the seventh day, cells were treated for 24 hours with or in combinations of $100 \mu \mathrm{M} \mathrm{BC}$ and $10 \mathrm{nM}$ $\mathrm{E}_{2}$, as well as antihormones at $1 \mu \mathrm{M}$ of pure ER antagonist, ICI, and $1 \mu \mathrm{M}$ Tamoxifen (TAM). Treatment combinations are as follows: $\mathrm{E}_{2}, \mathrm{ICI}, \mathrm{E}_{2}+\mathrm{ICI}, \mathrm{BC}, \mathrm{BC}+\mathrm{E}_{2}, \mathrm{BC}+\mathrm{ICI}$, TAM, BC + TAM, $\mathrm{E}_{2}+$ TAM. Following protein extraction, quantification via the Bradford method, SDS-PAGE, and Western blot analysis were performed. Figure 4 illustrates the results from the Western blot for ER $\alpha$ protein expression of the previously mentioned treatment combinations. In comparison to control, treatments of $\mathrm{E}_{2}$ alone and $\mathrm{BC}+$
TAM showed a slight decrease of protein expression, but not of significance. Treatment of $E_{2}+$ TAM shows significant downregulation of $\mathrm{ER} \alpha$ protein expression in comparison to control. However, when compared to control, ICI, $\mathrm{E}_{2}+$ $\mathrm{ICI}, \mathrm{BC}, \mathrm{BC}+\mathrm{E}_{2}$, and $\mathrm{BC}+\mathrm{ICI}$ showed highly significant downregulation of ER $\alpha$ protein expression. Treatment with TAM alone showed exceedingly significant upregulation of ER $\alpha$ protein expression.

Figure 5 illustrates the results of PR-A/B expression with cell culture and treatment combinations as previously described. When compared to the control, $\mathrm{E}_{2}$ and $\mathrm{E}_{2}+\mathrm{TAM}$ show significant upregulation of PR levels. Significant downregulation of $\mathrm{PR}$ is observed with treatment combinations $\mathrm{BC}, \mathrm{BC}+\mathrm{ICI}$, and BC + TAM. Treatments of ICI, $\mathrm{E}_{2}+\mathrm{ICI}$, and TAM show a slight, but not significant, decrease in PR levels. There is a minor increase in PR levels when cells are treated with $\mathrm{BC}+$ $\mathrm{E}_{2}$ that is also not of significance when compared to the control.

\section{Effects of hormones and antihormones with $B C$ on cell viability}

T-47D cellular viability was also assessed under treatment combinations that were previously mentioned with hormones and antihormones. Cells were cultured using the experimental approach as indicated in "Cell viability assays" in "Materials and methods" section. Figure 6 illustrates the results of

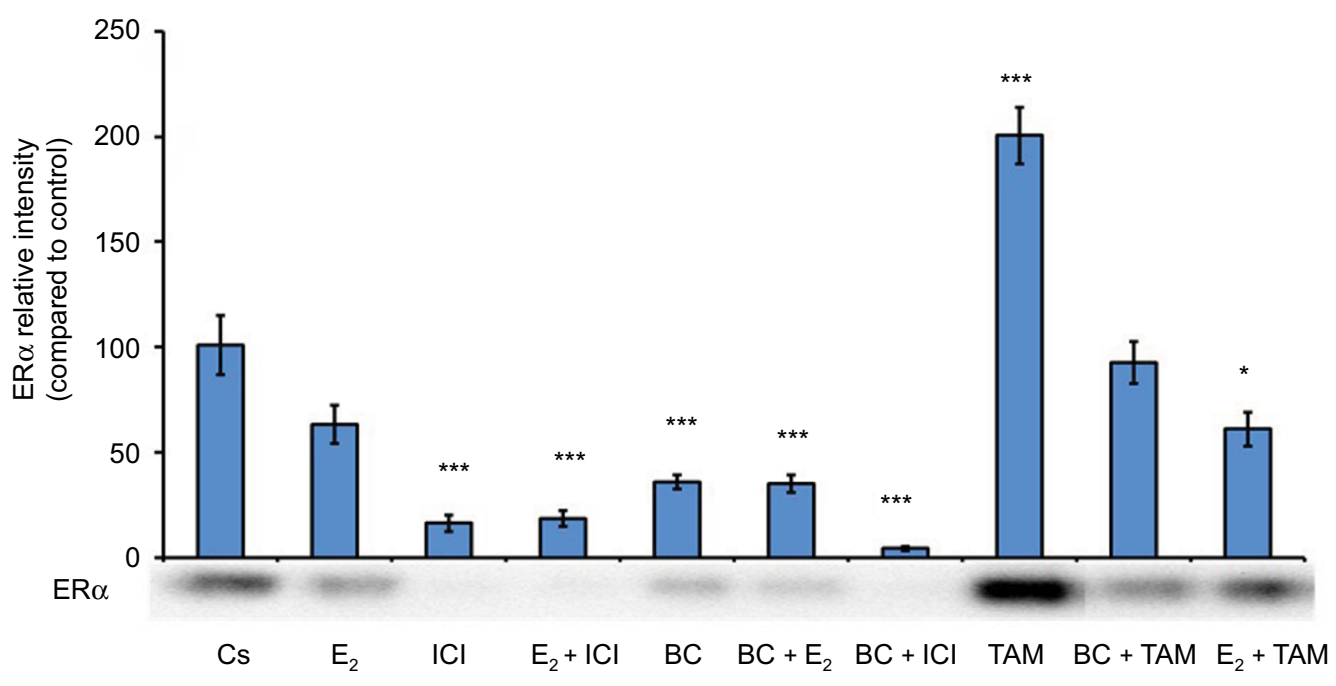

Figure 4 Effects of hormones and antihormones with $B C$ on $E R \alpha$ levels.

Notes: T-47D cell cultures were prepared as stated in Figures I and 2. On the seventh day, cells were treated with or in combinations of I00 $\mu M$ BC, I0 nM $E_{2}$, I $\mu M$ of pure ER antagonist, ICl, and I $\mu$ M TAM and incubated for 24 hours. Treatment combinations are as follows: $E_{2}, I C I, E_{2}+I C I, B C, B C+E_{2}, B C+I C l, T A M, B C+T A M, E_{2}+$ TAM. Cellular protein extracts were prepared followed by protein quantification, SDS-PAGE, and Western blot analysis. The control lane, Cs, represents cells grown in the absence of ligands in media containing 5\% DCC-stripped FBS. The relative intensity of ER $\alpha$ protein, as compared to Cs, is displayed as the mean \pm SEM. The asterisk indicates significant difference with respect to the control. ${ }^{*} p<0.05$ and ${ }^{* * *} p<0.00 \mathrm{I}$ (Kruskal-Wallis test followed by post hoc analysis using Mann-Whitney $U$ test). Three independent experiments are displayed in the representative blots.

Abbreviations: BC, black cohosh; Cs, control; ER $\alpha$, estrogen receptor-alpha; SEM, standard error of the mean; SDS, sodium dodecyl sulfate; PAGE, polyacrylamide gel electrophoresis; DCC, dextran-coated charcoal; FBS, fetal bovine serum; ICl, ICI I82, 780; TAM, Tamoxifen; $\mathrm{E}_{2}$, estradiol. 


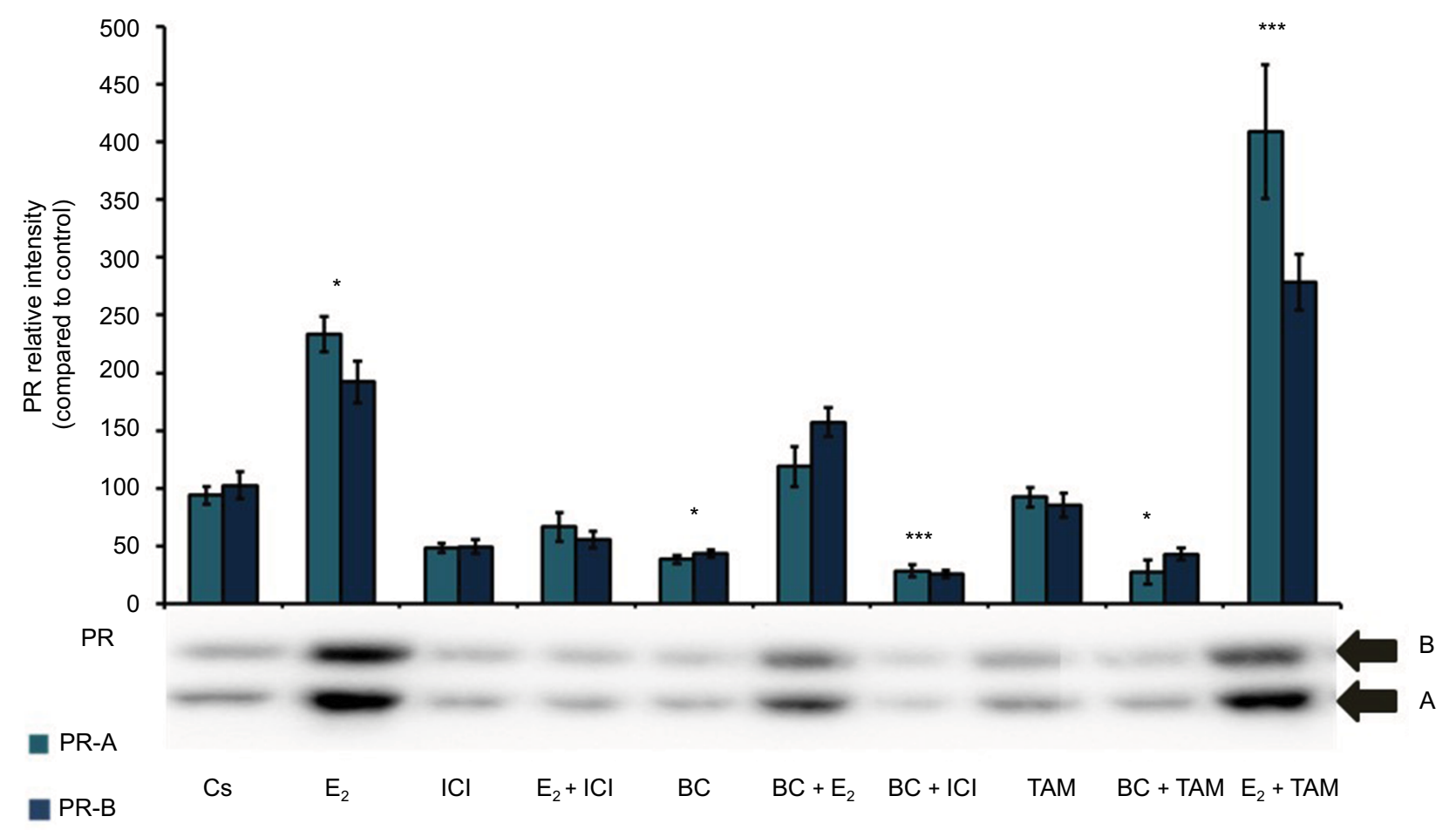

Figure 5 Effects of hormones and antihormones with BC on PR-A/B levels.

Notes: T-47D cell cultures were prepared as stated in Figures I and 2. On the seventh day, cells were treated for 24 hours with or in combinations of $100 \mu M$ BC, $10 \mathrm{nM}$ $\mathrm{E}_{2}$, I $\mu \mathrm{M}$ of pure ER antagonist, ICl, and I $\mu \mathrm{M}$ TAM. Treatment combinations are as follows: $\mathrm{E}_{2}, \mathrm{ICl}, \mathrm{E}_{2}+\mathrm{ICl}, \mathrm{BC}, \mathrm{BC}+\mathrm{E}_{2}, \mathrm{BC}+\mathrm{ICl}, \mathrm{TAM}, \mathrm{BC}+\mathrm{TAM}, \mathrm{E}_{2}+\mathrm{TAM}$. Cellular protein extracts were prepared followed by protein quantification, SDS-PAGE, and Western blot analysis. The control lane, Cs, represents cells grown in the absence of ligands in media containing 5\% DCC-stripped FBS. The relative intensity of PR-A/B protein, as compared to Cs, is displayed as the mean \pm SEM. The asterisk indicates significant difference with respect to the control. ${ }^{*} p<0.05$ and $* * * p<0.00 I$ (Kruskal-Wallis test followed by post hoc analysis using Mann-Whitney $U$ test). Three independent experiments are displayed in the representative blots.

Abbreviations: BC, black cohosh; Cs, control; PR, progesterone receptor; ER, estrogen receptor; SEM, standard error of the mean; SDS, sodium dodecyl sulfate; PAGE, polyacrylamide gel electrophoresis; DCC, dextran-coated charcoal; FBS, fetal bovine serum; ICI, ICI I82, 780; TAM, Tamoxifen; $\mathrm{E}_{2}$, estradiol.

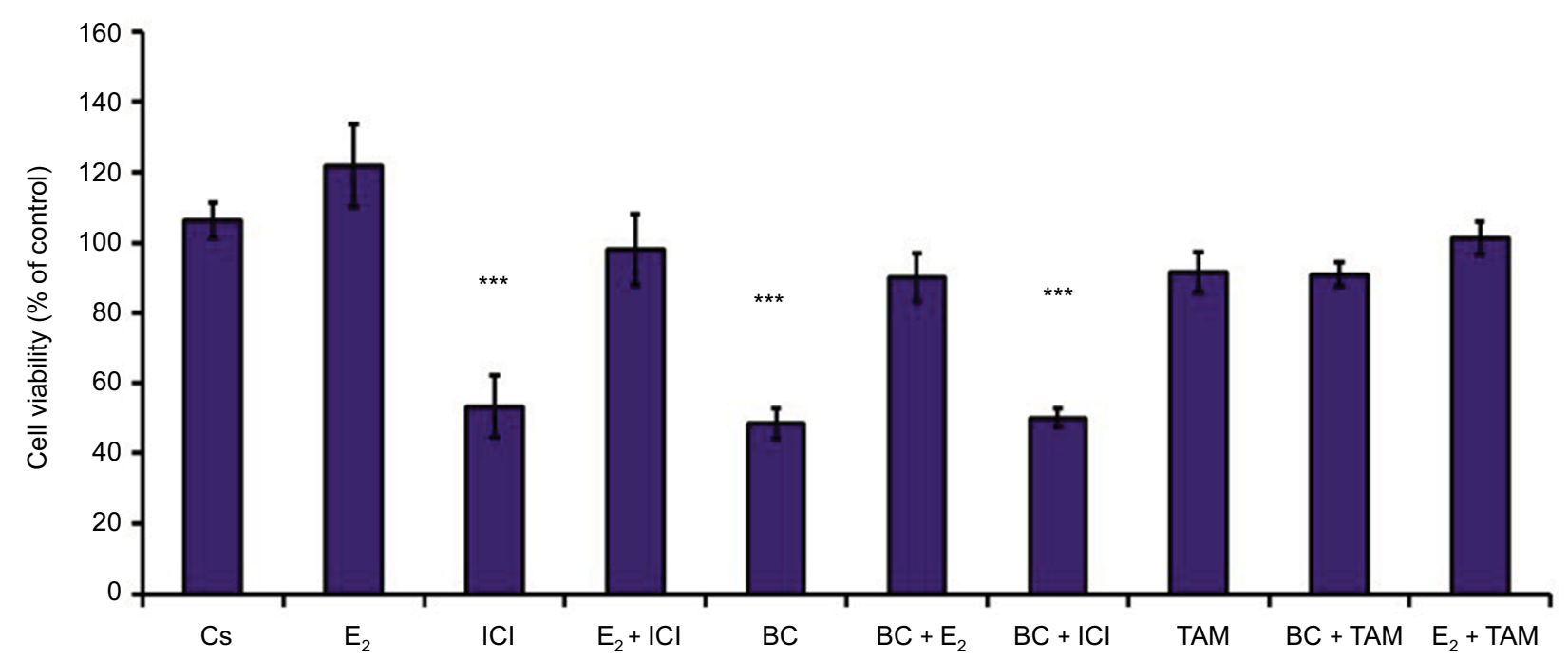

Figure 6 Effects of hormones and antihormones with BC on cell viability.

Notes: T-47D cells were cultured as mentioned in Figure 3. The treatments, alone or in combination, consisted of $100 \mu M B C, 10 \mathrm{nM} E_{2}$, I $\mu M$ of pure ER antagonist, ICI, and I $\mu$ M TAM. Treatment combinations are as follows: $E_{2}, I C I, E_{2}+I C l, B C, B C+E_{2}, B C+I C l, T A M, B C+T A M, E_{2}+T A M$. This was followed by a cell viability assay utilizing propidium iodide staining and image cytometry via the Nexcelom Cellometer Vision on the seventh day. $*_{* *} p<0.00 \mathrm{I}$ (Kruskal-Wallis test followed by post hoc analysis using Mann-Whitney $U$ test). Three independent experiments are displayed in the graph.

Abbreviations: $B C$, black cohosh; Cs, control; ER, estrogen receptor; ICI, ICI I82, 780; TAM, Tamoxifen; $E_{2}$, estradiol. 
the treatment combinations compared to the control. As mentioned previously, $\mathrm{E}_{2}$ is an ER agonist; therefore, it is expected that this compound will induce cell proliferation in hormone-dependent T-47D cells. Results in Figure 6 also signify that treatment of BC alone significantly reverses cell proliferation; it is also seen with treatments of ICI alone and in the combination of BC + ICI. Treatment with $\mathrm{E}_{2}+\mathrm{ICI}, \mathrm{BC}$ $+\mathrm{E}_{2}$, TAM, BC + TAM, and $\mathrm{E}_{2}+\mathrm{TAM}$, when compared to control, shows no cellular reduction.

\section{Effects of BC on ESR I levels}

RT-qPCR was utilized to study the effects of BC on the levels of ER $\alpha$ under various conditions. ESR1 gene expression was normalized to reference genes, HPRT-1 and ACTB, in T-47D cells exposed to treatment conditions for 24 hours. These results depicted in Figure 7 show that ESR1 expression was reduced with $10 \mathrm{nM} \mathrm{E}_{2}$ but increased with $100 \mu \mathrm{M} \mathrm{BC}$, and in combination with $\mathrm{E}_{2}$ and $\mathrm{BC}$. The effects observed by $\mathrm{BC}$ and ICI combination induced a $30 \%$ decrease in ESR1

A

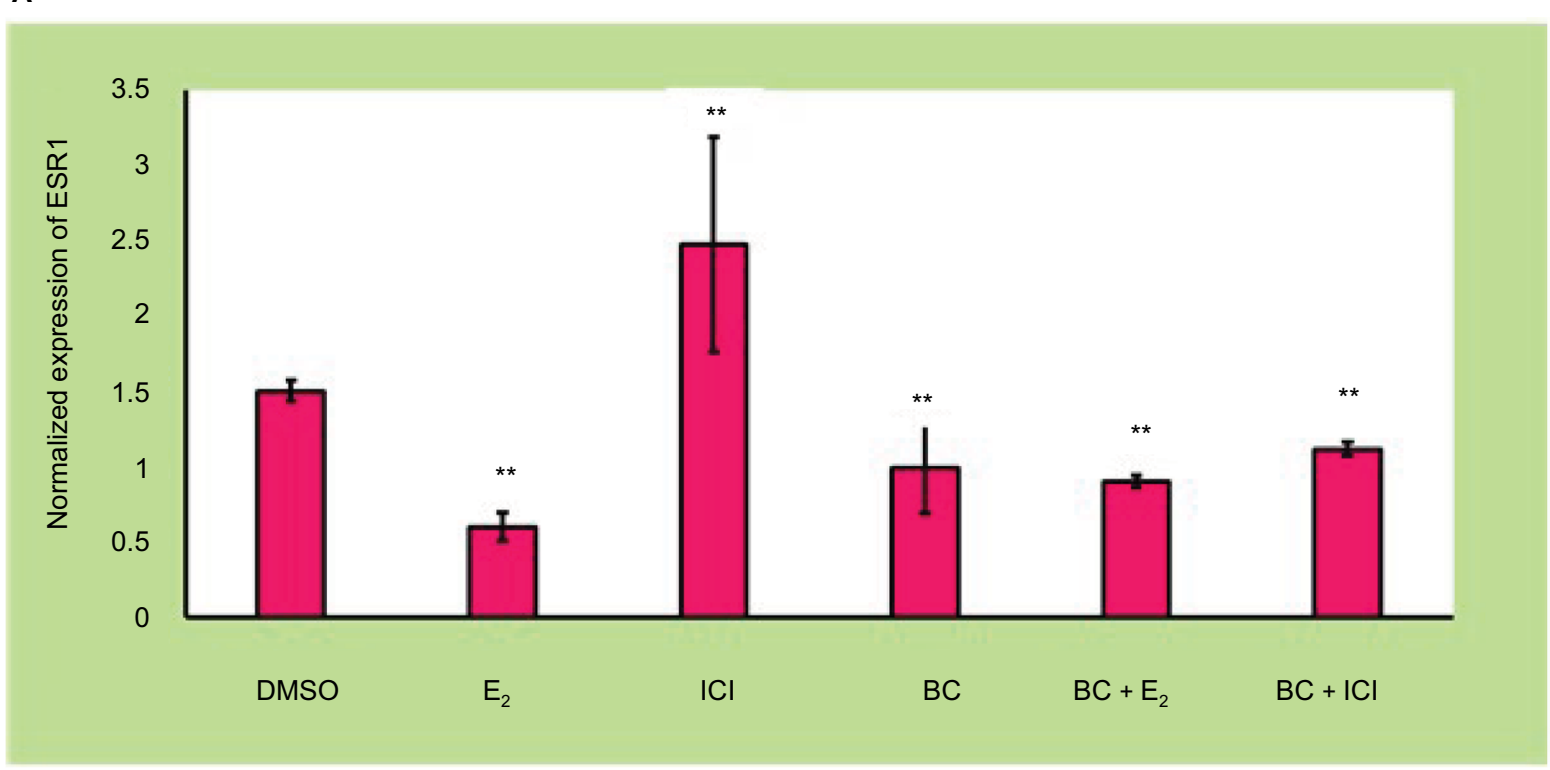

B

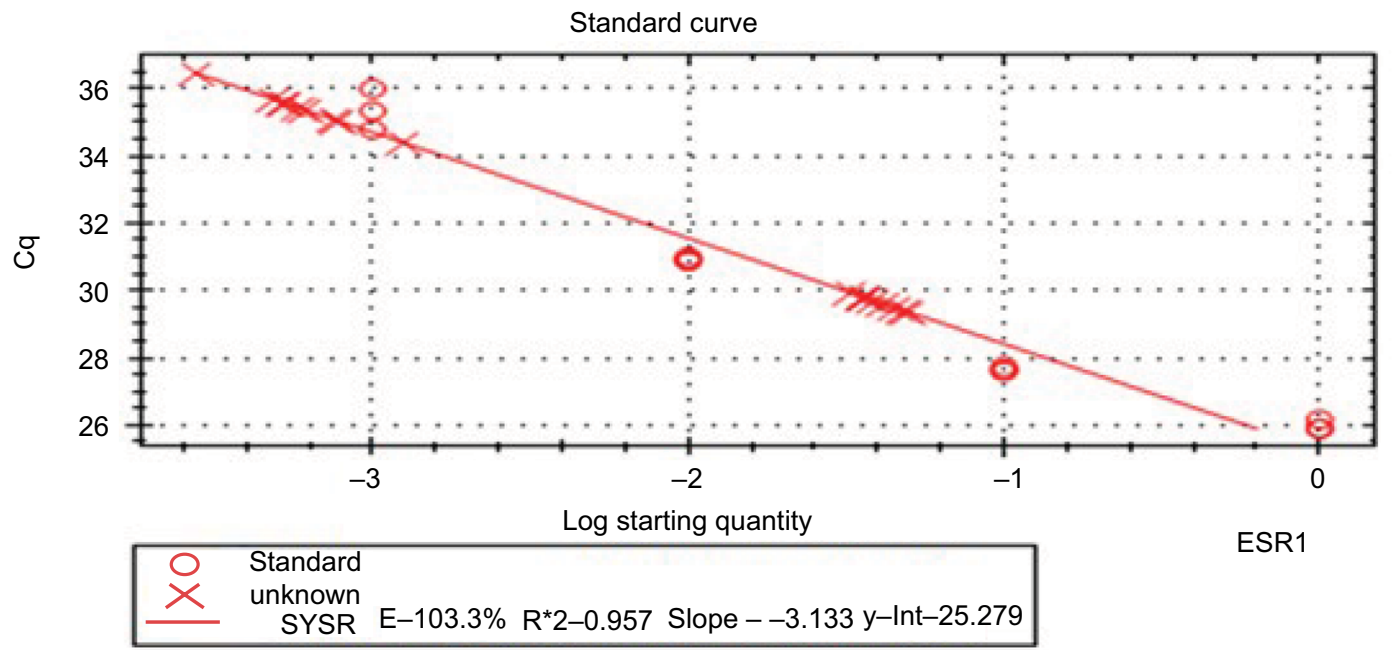

Figure 7 Effects of BC on ESRI gene expression.

Notes: $(A)$ The effect of $B C, E_{2}$, and ICl alone and in combination on ESRI mRNA levels in T-47D breast cancer cells was determined by RT-qPCR. T-47D cells were treated in the presence or absence of $100 \mu \mathrm{M} \mathrm{BC}, 10 \mathrm{nM} \mathrm{E}$, and/or I $\mu \mathrm{M} \mathrm{ICl}$ for 24 hours. Results are shown as the mean \pm SEM of at least three independent experiments with three replicates in each experiment. $* p<0.05$ (Kruskal-Wallis test followed by post hoc analysis using Mann-Whitney $U$ test). (B) Calculation of PCR efficiencies. RT-qPCR efficiencies of reference ACTB and HPRT-I genes and target gene (ESRI) were determined. Cq was plotted against the log amount of cDNA input. Amplification efficiencies were calculated according to the equation $E=10^{(-1 / \text { slope })}$.

Abbreviations: BC, black cohosh; SEM, standard error of the mean; ICI, ICI I82, 780; $\mathrm{E}_{2}$, estradiol; RT-qPCR, reverse transcription quantitative real-time polymerase chain reaction; Cq, quantification cycle; DMSO, dimethyl sulfoxide; SYSR, SsoAdvanced SYBR Green Supermix. 
expression levels as compared to the dimethyl sulfoxidetreated control.

\section{Effects of BC on the cellular localization of ER}

With the use of confocal microscopy, the cytolocalization of ER $\alpha$ was determined to be located within the nuclei of T-47D cells as shown in Figure 8. To stain the nuclei of the cells, 4',6-diamidino-2-phenylindole (DAPI; blue) immunofluorescent stain was used, and Cy3 (red) immunofluorescent stain was used for ER $\alpha$ protein. Furthermore, the control group (Cs) is a representation of cells cultured in 5\% DCC-FBS. Treatments included $100 \mu \mathrm{M} \mathrm{BC}$ alone or in combination with $10 \mathrm{nME}_{2}, 1 \mu \mathrm{M}$ ICI, and $1 \mu \mathrm{M}$ TAM. Treatment of cells with $10 \mathrm{nM} \mathrm{E}_{2}$ decreased $\mathrm{ER} \alpha$ nuclear intensity compared to Cs. The addition of $1 \mu \mathrm{M}$ ICI with $\mathrm{E}_{2}$ reduced the intensity of immunolocalization of $\mathrm{ER} \alpha$ to a greater extent from the $\mathrm{E}_{2}$-induced treatment. When cells were treated with $100 \mu \mathrm{M}$ $\mathrm{BC}$, a reduced level of $\mathrm{ER} \alpha$ intensity was observed. $\mathrm{E}_{2}$ and $\mathrm{BC}$ treatment did not increase the $\mathrm{ER} \alpha$ level compared to $\mathrm{E}_{2}$ alone. Treatment with ICI, TAM, and BC reduced the ER $\alpha$ levels compared to $\mathrm{Cs}$, also indicating an ER $\alpha$-dependent mechanism at this concentration.

\section{Discussion}

Many women are taking botanicals such as BC to relieve menopausal symptoms of hot flashes, profuse sweating, and sleep disturbances. ${ }^{6,7}$ They have turned to botanicals due to the increased anxiety over the risks of traditional hormonal therapy. ${ }^{20} \mathrm{BC}$ is a phytoestrogen, which may possess estrogenic or antiestrogenic effects in the human body. Phytoestrogens are a class of chemicals found naturally in certain plants that mimic the action of estrogen. ${ }^{10}$ In this study, the effects of $\mathrm{BC}$ alone and in combination with hormones and antihormones were examined with cellular viability and expression of ER $\alpha$ and PR-A/B in ER (+) T-47D breast cancer cells.

Our results demonstrated that $8 \% \mathrm{BC}$ induced a concentration-dependent decrease in both ER $\alpha$ and PR-A/B protein levels, with optimal reduction occurring at $100 \mu \mathrm{M}$. As for effects of hormones and antihormones with $\mathrm{BC}$ on ER $\alpha$ protein levels, the results of this study demonstrate that $\mathrm{ER} \alpha$ protein levels were downregulated with the treatment of $10 \mathrm{nM} \mathrm{E}_{2}$. Likewise, when BC was used alone, ER $\alpha$ was downregulated when compared to the control, which may suggest a possible ER $\alpha$-mediated mechanism of action. When treatments of ICI were used alone or in combinations of $\mathrm{ICI}+\mathrm{E}_{2}$ and $\mathrm{BC}+\mathrm{ICI}$, its effects on $\mathrm{ER} \alpha$ resulted in downregulation when compared to the control, which is expected, due to ICI's pure antagonist properties. When BC was used with TAM, ER $\alpha$ protein levels were downregulated when compared to the control, as they are seen when 10 $\mathrm{nM} \mathrm{E}_{2}$ and TAM were used. This, once again, may suggest a possible ER $\alpha$-mediated mechanism of action. As for the effects of hormones and antihormones with $\mathrm{BC}$ on $\mathrm{PR}-\mathrm{A} / \mathrm{B}$ levels, $\mathrm{E}_{2}$ treatment alone and in combination $\left(\mathrm{BC}+\mathrm{E}_{2}\right.$ and $\mathrm{E}_{2}+\mathrm{TAM}$ ) upregulates $\mathrm{PR}-\mathrm{A} / \mathrm{B}$ protein levels when compared to the control, demonstrating the effects estrogen has on $\mathrm{PR}$ levels. Treatment of BC alone and BC + TAM downregulates PR-A/B levels when compared to the control. This may suggest that the properties of $\mathrm{BC}$ act through an independent pathway, $\mathrm{E}_{2}$ on PR.

Cell viability assays showed a decrease in cell viability pattern upon treatment with $5-100 \mu \mathrm{M}$ of BC as compared to the control. The maximal effect was observed at $100 \mu \mathrm{M}$ with only $28 \%$ of viable cells remaining, indicating that high concentrations of $\mathrm{BC}$ inhibited cell division. These results indicate that the reduction of cell viability, after treatment

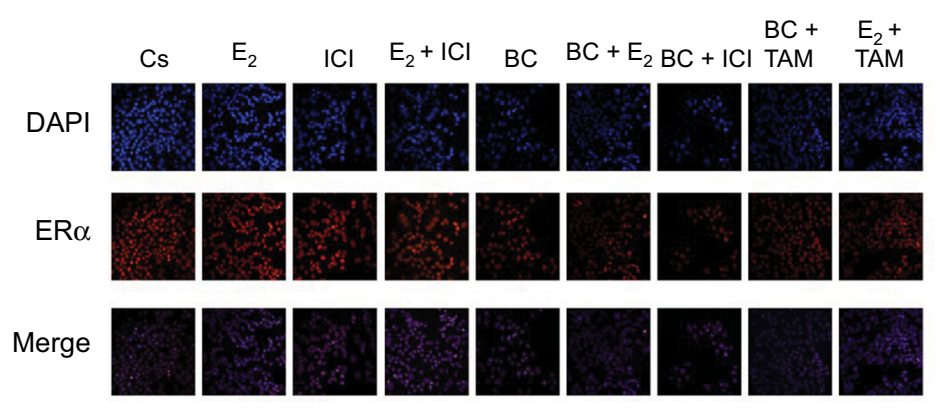

Figure 8 Effects of $B C$ on the cellular localization of ER $\alpha$.

Notes: Treated T-47D cells were grown in 12-well growth plates, each well containing $\sim 30,000$ cells on coverslips. The cells were sustained for 2 days in whole media containing $10 \%$ FBS. They were then withdrawn from endogenous growth factors by culturing in DCC-FBS for 6 days. $E_{2}, I C l$, BC, and TAM were added in 2-day intervals alone or in combination for a period of 6 days. Cells were treated with Cy3 (red) and DAPI (blue) immunofluorescent stains and the cytolocalization of ER $\alpha$ protein was determined using confocal microscopy.

Abbreviations: BC, black cohosh; Cs, control; ER $\alpha$, estrogen receptor-alpha; DCC, dextran-coated charcoal; FBS, fetal bovine serum; ICI, ICI I82, 780; TAM, Tamoxifen; $E_{2}$, estradiol. 
with $\mathrm{BC}$, may correlate with the downregulation of $\mathrm{ER} \alpha$ and PR-A/B protein expression, as observed in the Western blot analyses. The proliferative effect of $\mathrm{E}_{2}$ in $\mathrm{T}-47 \mathrm{D}$ cells was reversed by treatments with $\mathrm{ICI}, \mathrm{BC}$, and the combination of $\mathrm{BC}+\mathrm{ICI}$, demonstrating a significant reduction of cell viability. These results may suggest that BC has an antiproliferative effect.

Images acquired through confocal microscopy reveal the cytolocalization of ER $\alpha$ remains within the nuclei of T-47D cells. Treatment of cells with $10 \mathrm{nM} \mathrm{E}_{2}$ decreased ER $\alpha$ nuclear intensity compared to the control (Cs). The addition of $1 \mu \mathrm{M}$ ICI with $\mathrm{E}_{2}$ significantly reduced the extent and intensity of immunolocalization of $\mathrm{ER} \alpha$ from the $\mathrm{E}_{2}$-induced treatment. When cells were treated with $100 \mu \mathrm{M} \mathrm{BC}$, a reduced level of $\mathrm{ER} \alpha$ intensity was observed and this correlates with the results of the Western blot analyses. $\mathrm{BC}+\mathrm{E}_{2}$ treatment decreased the $\mathrm{ER} \alpha$ intensity as compared to the control, once again correlating with the results of the Western blot analyses. Treatment with $\mathrm{BC}+\mathrm{ICI}$ decreased the ER $\alpha$ nuclear intensity, as is expected, due to ICI's pure antagonist properties. TAM and $\mathrm{BC}$ reduced the $\mathrm{ER} \alpha$ levels compared to $\mathrm{Cs}$, also indicating an ER $\alpha$-dependent mechanism at this concentration.

ESR1 gene expression levels were reduced with the treatment of $10 \mathrm{nME}_{2}, 100 \mu \mathrm{MBC}$, and $\mathrm{BC}$ in combination with $\mathrm{E}_{2}$. Consistent with our findings, $\mathrm{BC}$ appears to decrease proteins that are involved in translation. Based on the observations of $\mathrm{BC}$ effects on cell viability and ER and PR protein expression, concentration-dependent alterations in the sensitivity of both estrogens and antiestrogens in our results, along with our laboratory's previous study results, there is a possibility that a dual mechanism for $\mathrm{BC}$ is both $\mathrm{ER}$ dependent and independent. ${ }^{17,19}$

\section{Conclusion}

$\mathrm{BC}$ may be a modulator for a receptor that exhibits concentration-dependent functional selectivity as well as cross-talk with $\mathrm{ER} \alpha$ and $\mathrm{PR}-\mathrm{A} / \mathrm{B}$. It is clear that $\mathrm{BC}$ regulates the steroid receptors on a molecular level; understanding the dose-response relationship of BC may aid in the development of more selective ER agonist and antagonist mechanisms. While further studies are necessary, our results support the potential of $\mathrm{BC}$ as a preventative measure against breast cancer initiation and progression.

\section{Acknowledgments}

We would like to thank Meghan Quigley for her technical assistance. We would also like to thank Naturex (NJ, USA) for their donation of BC. Funding was provided by the Center of Biomedical Research and Prevention Research Center at Oakland University (Rochester, MI, USA).

The abstract of this paper was presented at the 97th Annual Meeting of the Endocrine Society at San Diego, CA, USA, on March 5-8, 2015, as a poster presentation with interim findings (presentation number: FRI-298; http://www. endocrine.org/meetings/endo-annual-meetings/abstractdetails?ID=20489). The poster's abstract was published in "Poster Abstracts" in the meeting proceedings.

\section{Disclosure}

The authors report no conflicts of interest in this work.

\section{References}

1. Dietz BM, Hajirahimkhan A, Dunlap TL, Bolton JL. Botanicals and their bioactive phytochemicals for women's health. Pharmacol Rev. 2016;68(4):1026-1073.

2. Lumachi F, Brunello A, Maruzzo M, Basso U, Basso SM. Treatment of estrogen receptor-positive breast cancer. Curr Med Chem. 2013;20(5):596-604

3. Taylor M. Complementary and alternative approaches to menopause. Endocrinol Metab Clin North Am. 2015;44(3):619-648.

4. Smith T, Lynch ME, Johnson J, Kawa K, Bauman H, Blumenthal M. Herb supplement sales increase $6.8 \%$ in 2014. HerbalGram. 2015;107:52-59.

5. Borrelli F, Izzo AA, Ernst E. Pharmacological effects of Cimicifuga racemosa. Life Sci. 2003;73(10):1215-1229.

6. Blumenthal M. The use of black cohosh to treat symptoms of menopause. Sex Reprod Menopause. 2004;2(1):27-34.

7. Einbond LS, Wen-Cai Y, He K, et al. Growth inhibitory activity of extracts and compounds from Cimicifuga species on human breast cancer cells. Phytomedicine. 2008;15(6-7):504-511.

8. Wuttke W, Jarry H, Becker T, et al. Phytoestrogens: endocrine disrupters or replacement for hormone replacement therapy? Maturitas. 2003;44(Suppl 1):S9-S20.

9. Manavathi B, Dey O, Gajulapalli VN, Bhatia RS, Bugide S, Kumar R. Derailed estrogen signaling and breast cancer: an authentic couple. Endocr Rev. 2013;34(1):1-32.

10. Oseni T, Patel R, Pyle J, Jordan VC. Selective estrogen receptor modulators and phytoestrogens. Planta Med. 2008;74(13):1656-1665.

11. Maximov PY, Lee TM, Jordan VC. The discovery and development of selective estrogen receptor modulators (SERMs) for clinical practice. Curr Clin Pharmacol. 2013;8(2):135-155.

12. Yip CH, Rhodes A. Estrogen and progesterone receptors in breast cancer. Future Oncol. 2014;10(14):2293-2301.

13. Wen DX, Xu YF, Mais DE, Goldman ME, McDonnell DP. The A and $\mathrm{B}$ isoforms of the human progesterone receptor operate through distinct signaling pathways within target cells. Mol Cell Biol. 1994;14(12):8356-8364.

14. Musgrove EA, Hamilton JA, Lee CS, Sweeney KJ, Watts CK, Sutherland RL. Growth factor, steroid, and steroid antagonist regulation of cyclin gene expression associated with changes in T-47D human breast cancer cell cycle progression. Mol Cell Biol. 1993;13(6):3577-3587.

15. Siebert AE, Sanchez AL, Dinda S, Moudgil VK. Effects of estrogen metabolite 2-methoxyestradiol on tumor suppressor protein p53 and proliferation of breast cancer cells. Syst Biol Reprod Med. 2011;57(6):279-287.

16. Dinda S, SanchezA, Moudgil VK. Effects of LY117018 (a SERM analog of raloxifene) on tumor suppressor proteins and proliferation of breast cancer cells. Horm Mol Biol Clin Investig. 2010;2(1):211-217. 
17. Hallman K, Aleck K, Dwyer B, et al. The effects of turmeric (curcumin) on tumor suppressor protein (p53) and estrogen receptor $(E R \alpha)$ in breast cancer cells. Breast Cancer (Dove Med Press). 2017;9:153-161.

18. Hallman K, Aleck K, Quigley M, et al. The regulation of steroid receptors by epigallocatechin-3-gallate in breast cancer cells. Breast Cancer (Dove Med Press). 2017;9:365-373.
19. Saluzzo J, Hallman KM, Aleck K, et al. The regulation of tumor suppressor protein, $\mathrm{p} 53$, and estrogen receptor $(\mathrm{ER} \alpha)$ by resveratrol in breast cancer cells. Genes Cancer. 2016;7(11-12):414-425.

20. Snelten CS, Dietz B, Bolton JL. Modulation of estrogen chemical carcinogenesis by botanical supplements used for postmenopausal women's health. Drug Discov Today Dis Mech. 2012;9(1):47-54.

\section{Publish your work in this journal}

Breast Cancer - Targets and Therapy is an international, peerreviewed open access journal focusing on breast cancer research, identification of therapeutic targets and the optimal use of preventative and integrated treatment interventions to achieve improved outcomes, enhanced survival and quality of life for the cancer patient
The manuscript management system is completely online and includes a very quick and fair peer-review system, which is all easy to use. Visit http://www.dovepress.com/testimonials.php to read real quotes from published authors. 